\title{
OPTIMASI PELAKSANAAN PROYEK KONSTRUKSI DENGAN METODE PERT DAN CPM
}

\author{
Amiruddin Hi. Muhammad \\ Dosen Fakultas Teknik Universitas Nuku Tidore \\ Email: amiruddinmuhammad293@gmail.com
}

\begin{abstract}
Implementation of a project work requires not only a reliable human resources, but also must be supported by a good management. Planning project activities is an issue that is very important because it is the basis for project planning in order to be able to finish the projects implemented with time and cost optimal. Method PERT and CPM is a management tool that is associated with the planning and control of costs and time on a project. Both of these methods can be applied in carrying out the project, so that all work can be run according to plan and provide more satisfactory results.

The purpose of this study was to evaluate the time and cost Development Project Market Sarimalaha Tidore Islands, North Maluku. In searching for the possibility of achieving time a project that has been planned in the schedule with the analysis using PERT method and analyze the time and cost of the project through the acceleration of activity using CPM method. The data used data is market development project Sarimalaha Tidore Islands..

From the research that has been carried out showed that that the possibility of the project is completed in accordance with the Time scedulle based analysis using PERT method amounted to $98.42 \%$. For the analysis of acceleration events with CPM method showed that that the maximum acceleration of the process of acceleration occurs when the project can be accelerated up to 162,17 days from 170 days when the original plan and the cost of the project rose to Rp.8.857.795.386,00 of plan costs prior to acceleration is Rp.8,775,686,914.00. Thus a reduction in project time for 7,83 days and increase the cost of Rp.82.108.472,00 at the time of reaching the maximum acceleration.
\end{abstract}

Keywords: Planning, Time schedule, Method PERT and CPM, Market Development Project Sarimalaha Tidore Islands, North Maluku. 


\section{INTISARI}

Pelaksanaan pekerjaan suatu proyek membutuhkan tidak hanya sumber daya manusia yang handal, tetapi juga harus didukung dengan suatu manajemen yang baik. Perencanaan kegiatan proyek merupakan masalah yang sangat penting karena perencanaan merupakan dasar untuk proyek agar proyek yang dilaksanakan dapat selesai dengan waktu dan biaya yang optimal. Metode PERT dan CPM merupakan alat bantu manajemen yang berkaitan dengan perencanaan dan pengendalian biaya dan waktu pada suatu proyek. Kedua metode tersebut dapat diterapkan dalam melaksanakan proyek, sehingga semua pekerjaan dapat berjalan menurut rencana dan memberikan hasil yang lebih memuaskan.

Tujuan dari penelitian ini untuk mengevaluasi waktu dan biaya Proyek Pembangunan Pasar Sarimalaha Kota Tidore Kepulauan, Maluku Utara. Dalam mencari kemungkinan tercapainya waktu proyek yang telah direncanakan dalam time schedulle dengan analisis menggunakan metode PERT dan menganalisis waktu dan biaya proyek melalui percepatan kegiatan dengan menggunakan CPM. Data yang digunakan adalah data Proyek Pembangunan Pasar Sarimalaha Kota Tidore Kepulauan.

Dari penelitian yang telah dilakukan didapatkan hasil yaitu bahwa kemungkinan proyek selesai sesuai dengan Time scedulle berdasarkan analisis dengan memakai metode PERT adalah sebesar 98,42\%. Untuk analisis percepatan kegiatan dengan metode CPM didapatkan hasil yaitu bahwa pada proses percepatan terjadi percepatan maksimum pada saat proyek dapat dipercepat hingga 162,17 hari dari waktu rencana semula 170 hari dan biaya proyek naik menjadi Rp.8.857.795.386,00 dari rencana biaya sebelum dilakukan percepatan yaitu Rp.8.775.686.914,00. Dengan demikian terjadi pengurangan waktu proyek selama 7,83 hari dan kenaikkan biaya sebesar Rp.82.108.472,00 pada saat percepatan mencapai maksimum.

Kata kunci : Perencanaan, Time Schedulle, Metode PERT dan CPM, Proyek Pembangunan Pasar Sarimalaha Kota Tidore Kepulauan, Maluku Utara. 


\section{PENDAHULUAN \\ Latar Belakang}

Pelaksanaan pekerjaan pada suatu proyek membutuhkan tidak hanya sumber daya manusia yang handal, tetapi juga suatu manajemen yang baik. Metode PERT (Program Evaluation and Review Technique) dan CPM (Critical Path Method) merupakan alat bantu dalam manajemen yang berkaitan dengan perencanaan dan pengendalian suatu proyek.

Pada perencanaan proyek konstruksi, waktu dan biaya yang dioptimasikan sangat penting untuk diketahui. Hal yang harus dilakukan dalam optimasi waktu dan biaya adalah membuat jaringan kerja proyek (network), mencari kegiatan-kegiatan yang kritis dan menghitung durasi proyek.

Pada Metode PERT, penekanan diarahkan kepada usaha mendapatkan kurun waktu yang paling baik. Pada perencanaan dengan PERT, suatu proyek dibagi-bagi dalam banyak event dan kegiatan, yakni bagianbagian kecil dari pekerjaan dan untuk tiaptiap kegiatan ditentukan lainnya waktu yang diperlukan, sehingga seluruh pekerjaan direncanakan waktu penyelesaiannya dengan teliti. Metode CPM merupakan alat bantu dalam merencanakan dan mengendalikan waktu dan biaya, yaitu mengusahakan agar waktu penyelesaian suatu proyek dapat ditekan serendah mungkin, dalam arti yang dibutuhkan untuk menyelesaikan suatu pekerjaan, dan biaya yang dikeluarkan untuk mempercepat selesainya pekerjaan ini ditekan serendah mungkin.

Metode analisis jaringan kerja yang banyak digunakan oleh praktisi seperti CPM dan PERT dapat mengklasifikasikan kegiatan sebagai kritis dan tidak kritis. Suatu aktivitas adalah kritis jika pelaksanaan dari aktivitas itu tidak dapat ditunda, sebab jika waktu pelaksanaannya ditunda akan berakibat memperbesar total waktu penyelesaian dari proyek. Sedangkan aktivitas yang tidak kritis adalah kebalikan dari aktivitas kritis, dalam hal pelaksanaannya dapat ditunda untuk suatu limit tertentu tanpa berpengaruh terhadap waktu penyelesaiannya proyek secara keseluruhan.

\section{Rumusan Masalah}

1. Berapa durasi optimal pelaksanaan proyek pembangunan Pasar Sarimalaha di Kota Tidore kepulauan?

2. Berapa total biaya proyek pembangunan Pasar Sarimalaha di Kota Tidore Kepulauan?

\section{Tujuan penelitian}

1. Menyusun jadwal kegiatan proyek dengan pertimbangan waktu penyelesaian proyek dan menentukan waktu penyelesaian tercepat.

2. Mencari kemungkinan tercapainya waktu proyek yang telah direncanakan dalam Time Schedule dengan analisis menggunakan Metode PERT.

3. Menganalisis waktu dan biaya proyek melalui percepatan kegiatan dengan menggunakan Metode CPM.

\section{Manfaat penelitian}

Mengetahui teknik penjadwalan yang baik untuk mengatur dan mengorganisasikan kegiatan-kegiatan dalam proyek.

\section{TINJAUAN PUSTAKA Proyek Konstruksi}

Menurut Ervianto (2002) proyek konstruksi merupakan suatu rangkaian kegiatan yang hanya satu kali dilaksanakan dan umumnya berjangka waktu pendek. Dalam rangkaian kegiatan tersebut, terdapat suatu proses yang mengolah sumber daya proyek menjadi suatu hasil kegiatan yang berupa bangunan. Proses yang terjadi dalam rangkaian kegiatan tersebut tentunya melibatkan pihak-pihak yang terkait, baik secara langsung maupun secara tidak langsung.

\section{Manajemen Proyek}

Ervianto (2002) menyatakan bahwa manajemen proyek adalah semua 
perencanaan, pelaksanaan, pengendalian, dan koordinasi suatu proyek dari awal (gagasan) hingga berakhirnya proyek untuk menjamin proyek secara tepat waktu, tepat biaya, dan tepat mutu.

\section{CPM (Critical Path Method)}

CPM pada dasarnya menitikberatkan pada persoalan keseimbangan antara biaya dan waktu penyelesaian proyek-proyek yang besar. Dengan CPM, jumlah waktu yang diperlukan untuk menyelesaikan berbagai taraf daripada proyek dianggap diketahui dengan pasti; lebih-lebih hubungan antara jumlah sumber-sumber yang digunakan dan waktu yang diperlukan untuk menyelesaikan proyek juga dianggap diketahui. Sehingga, CPM juga dapat didefinisikan sebagai suatu analisa jaringan kerja yang berusaha mengoptimalkan biaya total proyek melalui pengurangan atau percepatan waktu penyelesaian total proyek yang bersangkutan.

\section{Jaringan Kerja (Network Planning)}

Network Planning (Jaringan Kerja) adalah alat yang digunakan untuk merencanakan, menjadwalkan dan mengendalikan kemajuan proyek. Diagram jaringan merupakan metode yang dianggap mampu menyuguhkan teknik dasar dalam menentukan urutan dan kurun waktu kegiatan, yang pada giliran selanjutnya dapat dipakai untuk memperkirakan waktu penyelesaian proyek. Secara keseluruhan (Gray dan Erik, 2007).

\section{Lintasan Kritis}

Menurut Ervianto (2002), untuk menentukan analisis jalur kritis dapat dilakukan dengan perhitungan ke depan (Forward Analysis) dan perhitungan ke belakang (Backward analysis). Dalam metode CPM (Critical Path Method), jika satu atau lebih aktifitas yang ada di jalur kritis tertunda, maka waktu penyelesaian seluruh proyek akan tertunda sebanyak waktu penundaan yang terjadi.

\section{PERT (Project Evaluation and Review Technique)}

PERT atau Project Evaluation and Review Technique adalah suatu metode yang bertujuan untuk sebanyak mungkin mengurangi adanya penundaan, maupun gangguan dan konflik produksi; mengkoordinasikan dan mensinkronisasikan berbagai bagian sebagai suatu keseluruhan pekerjaan; mempercepat selesainya proyek.

Bila CPM memperkirakan waktu komponen kegiatan proyek dengan pendekatan deterministik satu angka yang mencerminkan adanya kepastian, maka PERT direkayasa untuk menghadapi situasi dengan kadar ketidakpastian (uncertainty) yang tinggi pada aspek kurun waktu kegiatan (Soeharto, 1999, dalam Eka Dannyanti, 2010). Menurut Heizer dan Render (2005), dalam PERT digunakan distribusi peluang berdasarkan tiga perkiraan waktu untuk setiap kegiatan, antara lain waktu optimis (a), waktu pesimis (b), dan waktu realistis (m).

\section{Durasi Proyek}

Durasi proyek adalah jumlah waktu yang diperlukan untuk menyelesaikan seluruh pekerjaan proyek (Maharany dan Fajarwati, 2006).

Menjelaskan bahwa faktor yang berpengaruh dalam menentukan durasi pekerjaan adalah volume pekerjaan, metode kerja (construction method), keadaan lapangan, serta keterampilan tenaga kerja yang melaksanakan pekerjaan proyek. Durasi proyek adalah jumlah waktu yang diperlukan untuk menyelesaikan seluruh pekerjaan proyek.

\section{Analisis Optimasi}

Analisis Optimasi dapat diartikan sebagai suatu proses penguraian durasi proyek untuk mendapatkan percepatan durasi yang paling baik (optimal) dengan menggunakan berbagai alternatif ditinjau dari segi biaya. Proses memperpendek waktu kegiatan dalam jaringan kerja untuk mengurangi waktu pada jalur kritis, sehingga waktu penyelesaian total dapat dikurangi disebut sebagai crashing proyek (Heizer dan Render, 2005, dalam Eka Dannyanti, 2010). 


\section{METODE PENELITIAN}

\section{Variabel Penelitian}

Variabel secara umum dibagi menjadi dua, yaitu variabel independen dan variabel dependen. Variabel independen merupakan tipe variabel yang menjelaskan atau mempengaruhi variabel lain, sedangkan variabel dependen adalah tipe variabel yang dijelaskan atau dipengaruhi oleh variabel dependen.

Variabel yang digunakan dalam penelitian ini adalah variabel waktu optimal proyek sebagai variabel dependen, sedangkan variabel independennya, yaitu durasi proyek, hubungan ketergantungan antar kegatan proyek dan rencana anggaran biaya.

\section{Jenis dan Sumber Data}

\section{Jenis Data}

Jenis data yang dipakai dalampenelitian ini yaitu data kualitatif, data kuantitatif, data primer dan data sekunder.

\section{Sumber Data}

Dalam penelitian ini, dilakukan pada Proyek Pembangunan Pasar Sarimalaha di Kota Tidore Kepulauan, Provinsi Maluku Utara. Dan mengambil bahan penelitian dari Time Schedule (jadwal) pelaksanaan proyek, daftar harga satuan bahan dan upah tenaga kerja, analisis harga satuan dan rencana anggaran biaya (RAB) proyek. Data tersebut diperoleh dari Dinas Pekerjaan Umum (PU) Kota Tidore Kepulauan.

\section{Metode Pengumpulan Data}

Dalam suatu penelitian ilmiah, metode pengumpulan data dimaksudkan untuk memperoleh bahan-bahan yang relevan, akurat, dan terpercaya.

Metode pengumpulan data yang dipergunakan pada penelitian ini adalah:
a. Wawancara
b. Observasi Lapangan
c. Studi Pustaka

\section{Metode Analisis}

Keadaan yang dihadapi disini adalah adanya perbedaan umur pelaksanaan proyek dengan umur rencana proyek yang telah ditetapkan.

Optimasi waktu dan biaya yang akan dilakukan adalah mempercepat durasi proyek dengan penambahan biaya yang seminimal mungkin. Salah satu cara untuk mempercepat durasi proyek dalam istilah asingnya adalah crashing. Menurut Kusumah dan Wardhani (2008), terminologi proses crashing adalah dengan mereduksi durasi suatu pekerjaan yang akan berpengaruh terhadap waktu penyelesaian proyek. Proses crashing dipusatkan pada kegiatan yang berada pada lintasan kritis.

Percepatan durasi dapat dilakukan pada kegiatan-kegiatan yang dilalui oleh lintasan kritis. Ada beberapa cara untuk mempercepat suatu kegiatan, sehingga didapat alternatif terbaik sesuai dengan kondisi kontraktor pelaksana. Cara-cara tersebut misalnya:
a. Perubahan
hubungan
logika
ketergantungan antar kegiatan
b. Menambah sumber daya manusia
c. Melaksanakan kerja lembur
d. Menambah atau mengganti peralatan
e. Menambah ketersediaan material

\section{Metode CPM (Critical Path Method)}

Untuk menentukan waktu penyelesaian proyek, maka harus diidentifikasi apa yang disebut jalur kritis. Jalur (path) merupakan serangkaian aktivitas berhubungan yang bermula dari node awal ke node penyelesaian/akhir. Untuk menyelesaikan proyek, semua jalur harus dilewati. Oleh karena itu, harus ditentukan jumlah waktu yang dibutuhkan berbagai jalur tersebut.

Jalur terpanjang yang melewati, menentukan total waktu yang dibutuhkan untuk menyelesaikkan proyek. Jika aktifitas pada jalur terpanjang itu ditunda, maka seluruh proyek akan mengalami keterlambatan. Aktivitas jalur terpanjang merupakan aktivitas jalur kritis, dan jalur terpanjang itu disebut jalur kritis.

Setelah jalur kritis diketahui, langkah selanjutnya adalah melakukan percepatan proyek. Langkah-langkahnya adalah sebagai berikut: 
a. Menentukan waktu percepatan dan menghitung biaya tambahan untuk percepatan setiap kegiatan.

b. Mempercepat waktu penyelesaian proyek dengan mengutamakan kegiatan kritis yang memiliki slope biaya terendah. Apabila upaya percepatan dilakukan pada aktivitas-aktivitas yang tidak berada pada lintasan kritis, maka waktu penyelesaian keseluruhan tidak akan berkurang.

c. Susun kembali jaringan kerjanya.

d. Ulangi langkah kedua dan berhenti melakukan upaya percepatan apabila terjadi pertambahan lintasan kritis. Apabila terdapat lebih dari satu lintasan kritis, maka upaya percepatan dilakukan serentak pada semua aktivitas yang berada pada lintasan kritis. Usahakan agar tidak terjadi penambahan atau pemindahan jalur kritis apabila diadakan percepatan durasi pada salah satu kegiatan.

e. Upaya percepatan dihentikan apabila aktivitas-aktivitas pada lintasan kritis telah jenuh seluruhnya (tidak mungkin ditekan lagi).

f. Hitung biaya keseluruhan akibat percepatan untuk mengetahui total biaya proyek yang dikeluarkan.

Aspek biaya dalam penjadawalan proyek diperhitungkan karena adanya hubungan ketergantungan antara durasi waktu dengan biaya. Biaya yang dihitung adalah biaya langsung.

\section{Metode PERT}

Menurut Hayan (2005), triple duration estimate merupakan dasar perhitungan untuk PERT yang mempunyai asumsi dasar bahwa suatu kegiatan dilakukan berkali-kali, maka actual time akan membentuk distribusi beta dimana optimistic (waktu optimis) dan pessimistic duration (waktu pesimis) merupakan buntut (tail), sedangkan most likely duration (waktu realistis) adalah mode dari distribusi beta tersebut. Kemudian diasumsikan pendekatan dari durasi rata-rata yang disebut expected return (te) dengan

rumus sebgai berikut:

Waktu yang diharapkan (te) $=\frac{a+4 m+b}{6}$

te $=$ Expected duration

$\mathrm{a}=$ Waktu Optimis

$\mathrm{m}=$ Waktu realistis

$\mathrm{b}=$ Waktu Pesimis

Dengan menggunakan konsep te, maka jalur kritis dapat diindentifikas. Pada jalur kritis berlaku slack $=0$ (Soeharto, 1999).

Besarnya ketidakpastian tergantung pada besarnya angka a dan $b$, dirumuskan sebagai berikut:

Deviasi standar kegiatan:

$$
S=\frac{1}{6} \quad b-a
$$

$\mathrm{S}=$ Deviasi standar kegiatan

$\mathrm{a}=$ Waktu optimis

$\mathrm{b}=$ Waktu pesimis

Untuk variasi kegiatan dirumuskan sebagi berikut:

Varians kegiatan:

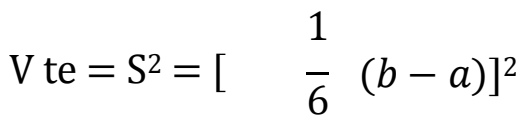

$\mathrm{V}(\mathrm{te})=$ Varians kegiatan

$\mathrm{S}=$ Deviasi standar kegiatan

$\mathrm{a}=$ Waktu optimis

$\mathrm{b}=$ Waktu pesimis

Untuk mengetahui kemungkinan tercapainya target jadwal dapat dilakukan dengan menghubungkan antara waktu yang diharapkan (TE) dengan target $T(d)$ yang dinyatakan dengan rumus: 


$$
\mathrm{Z}=\frac{T d-T E}{\mathrm{~S}}
$$

$\mathrm{Z}=$ Angka kemungkinan mencapai target

$\mathrm{T}(\mathrm{d})=$ Target jadwal

$\mathrm{TE}=$ Jumlah waktu kegiatan kritis

$\mathrm{S}=$ Deviasi standar kegiatan

Angka $\mathrm{z}$ merupakan angka probabilitas yang presentasenya dapat dicari dengan menggunakan table distribusi normal kumulatif $\mathrm{z}$.

\section{Diagram Alir Penelitian (Flow Chart)}

Tahapan penelitian secara skematis dilihat pada Gambar 3.1.dibawah ini:

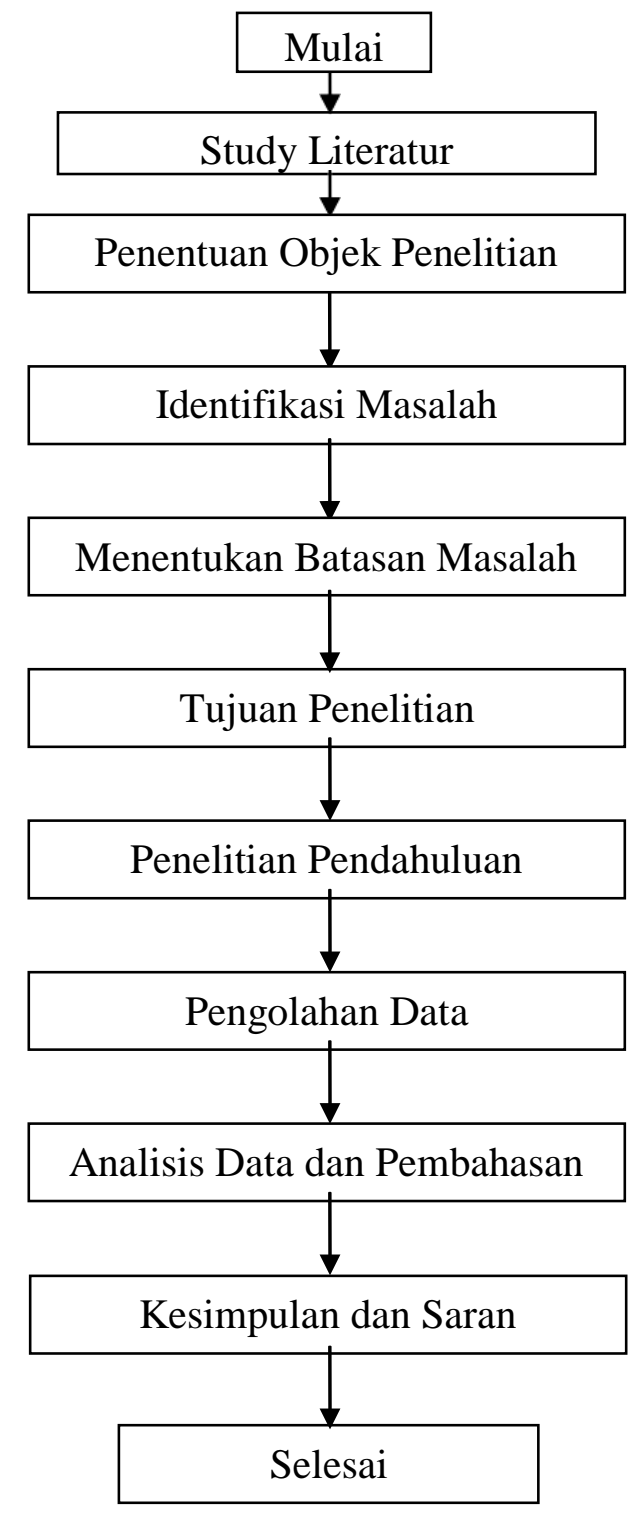

Gambar 3.1. Diagram Alir Penelitian (Flow

Chart)

\section{HASIL DAN PEMBAHASAN \\ Objek Penelitian}

Proyek Pembangunan Pasar Sarimahala yang berlokasi di daerah Kota Tidore Kepulauan Provinsi Maluku Utara ini, dijadikan sebagai sumber data proyek. Pada pelaksanaannya proyek ini dikerjakan oleh 3 (tiga) pihak Kontraktor, dengan total keseluruhan Pembangunan Pasar Sarimalaha ini Rp.52.253.695.000,.

Pengerjaannya bertahap dari tahun 2012 sampai 2014, hal ini dikarenakan keterbatasan anggaran APBD di Kota Tidore Kepulauan itu sendiri. Waktu pelaksanaanya 170 hari kelender kerja (7 hari kerja) untuk masing-masing tahap yang dimulai pada bulan januari dan selesainya pada bulan juli. Luas bangunan proyek $2197 \mathrm{~m} 2$ atau 2,1 hectar.

\section{Analisis Data}

Pada penelitian ini menggunakan metode PERT dan CPM guna menganalisis data yang sudah ada untuk mengetahui kemungkinan (\%) proyek dapat selesai sesuai time schedulle dan (\%) kemungkinan pengurangan waktu proyek dengan kenaikkan biaya yang minimal. Tentunya untuk menganalisis data yang banyak itu saya menggunakan perangkat lunak yaitu Microsoft Office Excel 2007 dan Microsoft Project 2007. Dengan memasukkan data dan perhitungan matematika sehingga memudahkan dalam pengerjaan ini.

\section{Penyusunan Jaringan Kerja (Network Planning)}

Pembangunan Pasar Sarimalaha yang mencangkup beberapa kegiatan utama. Tabel.4.1. di bawah ini menunjukkan daftar aktifitas utama, durasi dan biaya proyek. 
Tabel 4.1 . Daftar Aktivitas Utama, Durasi dan Biaya Proyek

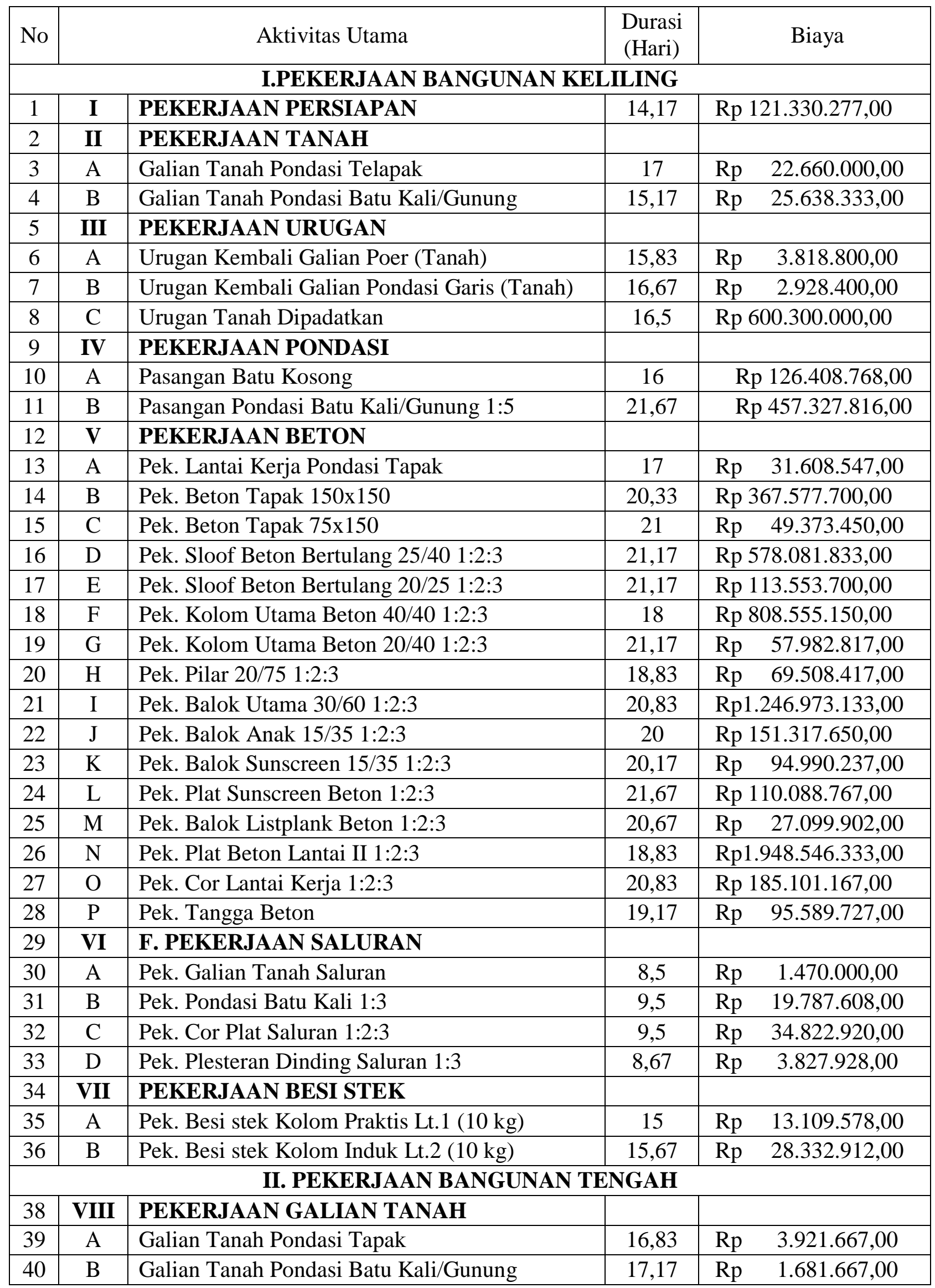




\begin{tabular}{|c|c|c|c|c|}
\hline 41 & IX & PEKERJAAN URUGAN & & \\
\hline 42 & $\mathrm{~A}$ & Urugan Kembali Galian Poer (Tanah) & 9,17 & $670.333,00$ \\
\hline 43 & $\mathrm{~B}$ & Urugan Kembali Galian Pondasi Garis (Tanah) & 8 & $529.600,00$ \\
\hline 44 & $\mathrm{C}$ & Urugan Tanah Dipadatkan & 7,17 & Rp $171.576 .667,00$ \\
\hline 45 & $\mathbf{X}$ & PEKERJAAN PONDASI & & \\
\hline 46 & A & Pasangan Batu Kosong & 16,67 & $38.867 .200,00$ \\
\hline 47 & $\mathrm{~B}$ & Pasangan Pondasi Batu Kali/Gunung 1:5 & 17,17 & Rp 123.654.856,00 \\
\hline 48 & $\mathbf{X I}$ & PEKERJAAN BETON & & \\
\hline 49 & A & Pek. Lantai Kerja Pondasi Tapak & 18,83 & $6.926 .880,00$ \\
\hline 50 & $\mathrm{~B}$ & Pek. Beton Tapak 150x150 & 21,5 & $\begin{array}{ll}\mathrm{Rp} & 61.881 .503,00\end{array}$ \\
\hline 51 & $\mathrm{C}$ & Pek. Beton Tapak 75x150 & 23,33 & $\mathrm{Rp} \quad 16.355 .219,00$ \\
\hline 52 & $\mathrm{D}$ & Pek. Sloof Beton Bertulang 25/40 1:2:3 & 22,33 & Rp 120.020.167,00 \\
\hline 53 & $\mathrm{E}$ & Pek. Sloof Beton Bertulang 20/25 1:2:3 & 21,17 & $\begin{array}{ll}\mathrm{Rp} & 14.708 .166,00\end{array}$ \\
\hline 54 & $\mathrm{~F}$ & Pek. Kolom Utama Beton 40/40 1:2:3 & 21,33 & Rp 157.966.500,00 \\
\hline 55 & $\mathrm{G}$ & Pek. Balok Utama 30/60 1:2:3 & 20,83 & $\operatorname{Rp} 219.199 .900,00$ \\
\hline 56 & $\mathrm{H}$ & Pek. Balok Anak 15/35 1:2:3 & 23,17 & $\begin{array}{ll}\mathrm{Rp} & 17.011 .400,00\end{array}$ \\
\hline 57 & I & Pek. Balok Sunscreen Beton 1:2:3 & 19 & $\begin{array}{ll}\mathrm{Rp} & 19.826 .500,00\end{array}$ \\
\hline 58 & $\mathrm{~J}$ & Pek. Plat Sunscreen Beton 1:2:3 & 17,17 & Rp $\quad 22.841 .167,00$ \\
\hline 59 & $\mathrm{~K}$ & Pek. Plat Beton Lantai II 1:2:3 & 21 & Rp 341.098.500,00 \\
\hline 60 & $\mathrm{~L}$ & Pek. Cor Lantai Kerja 1:2:3 & 17,83 & $\begin{array}{ll}\mathrm{Rp} & 20.939 .500,00\end{array}$ \\
\hline 61 & $\mathrm{M}$ & Pek. Tangga Beton & 17,17 & $\mathrm{Rp} \quad 36.863 .635,00$ \\
\hline 62 & XII & PEKERJAAN BESI STEK & & \\
\hline 63 & A & Pek. Besi stek Kolom Praktis Lt.1 (10 kg) & 15,67 & $\operatorname{Rp} \quad 19.292 .911,00$ \\
\hline \multirow[t]{2}{*}{64} & $\mathrm{~B}$ & Pek. Besi stek Kolom Induk Lt.2 (10 kg) & 15 & $\mathrm{Rp} \quad 44.249 .578,00$ \\
\hline & & Total & & Rp 8.857.795.386,00 \\
\hline
\end{tabular}

Sumber: Data Primer yang Diolah, 2015

Total waktu pengerjaan proyek Pasar Sarimalaha adalah 170 hari dengan total biaya proyek sebesar Rp. 8.857.795.386,00. Total biaya tersebut belum termasuk pajak. Biaya total setelah pajak sebesar Rp.9.743.574.000,00. Menurut laporan rencana anggaran biaya yang dibuat oleh kontraktor, biaya total proyek adalah Rp.9.652.474.000,00, sedangkan biaya total proyek yang dihasilkan dalam penelitian ini adalah Rp.9.735.364.000,00, hal ini disebabkan perhitungan pembulatan dua angka di belakang koma oleh Software Microsoft Project 2007.
Setelah komponen-komponen aktifitas proyek diketahui, selanjutnya dapat disusun jaringan kerjanya (network planning). Dalam proyek ini network planning disusun dengan menggunakan bantuan softwere Microsoft Project 2007 guna untuk menggambarkan jaringan proyek pembangunan Pasar Sarimalaha Kota Tidore Kepulauan yang sedang dibangun. Berikut ini penyusunan Network Diagram pembangunan proyek Pasar Sarimalaha pada Gambar 4.1. di bawah ini. 


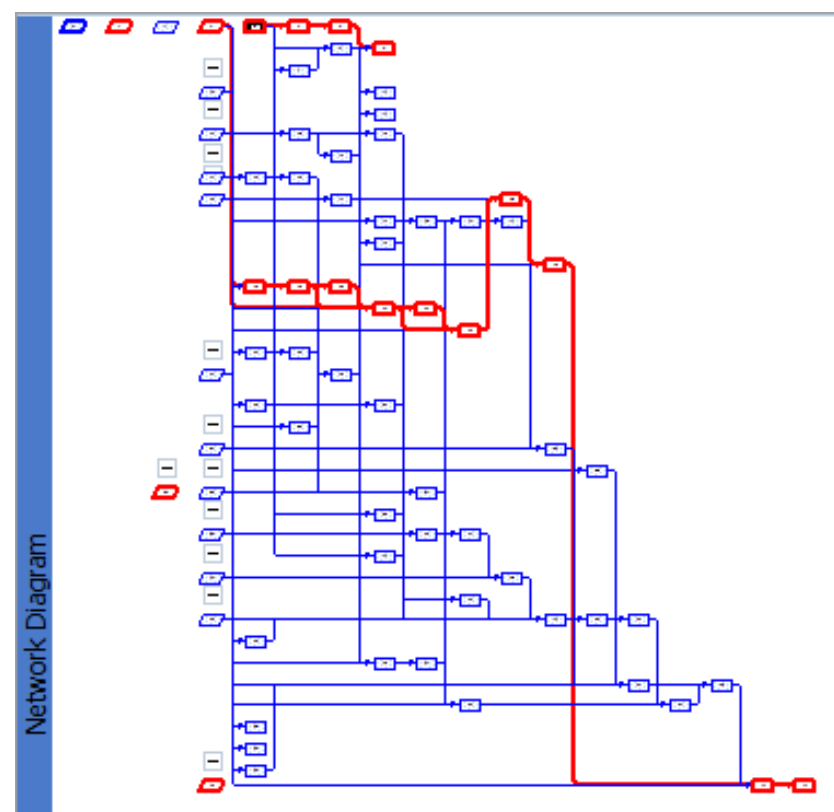

Gambar 4.1. Network Diagram Proyek Pasar Sarimalaha

\section{Jalur Kritis}

Jalur kritis adalah jalur yang terdiri dari kegiatan kritis. Jika dilihat dari prosedur menghitung umur proyek, maka total waktu jalur kritis sama dengan umur proyek. Oleh karena itu jalur kritis dapat didefinisikan sebagai jalur yang memiliki waktu terpanjang dari semua jalur yang dimulai dari peristiwa awal hingga peristiwa yang terakhir (Yamit : 1998).

Berdasarkan penyusunan Network Diagram di atas, maka dapat diketahui jalur kritis dari pelaksanaan Proyek Pembangunan Pasar Sarimalaha Kota Tidore Kepulauan, dapat dilihat pada Tabel 4.2. dibawah ini:

Tabel 4.2. Daftar Aktivitas Utama pada Lintasan Kritis

\begin{tabular}{|l|c|c|c|}
\hline \multicolumn{1}{|c|}{ Uraian Aktivitas Utama } & Free Slack & Total Slack & Keterangan \\
\hline Pekerjaan Persiapan & 0 days & 0 days & KRITIS \\
\hline Pek. Pilar 20/75 1:2:3 & 0 days & 0 days & KRITIS \\
\hline Pek. Balok Utama 30/60 1:2:3 & 0 days & 0 days & KRITIS \\
\hline Pek. Balok Anak 15/35 1:2:3 & 0 days & 0 days & KRITIS \\
\hline Pek. Balok Sunscreen 15/35 1:2:3 & 0 days & 0 days & KRITIS \\
\hline Pek. Plat Sunscreen Beton 1:2:3 & 0 days & 0 days & KRITIS \\
\hline Pek. Balok Listplank Beton 1:2:3 & 0 days & 0 days & KRITIS \\
\hline Pek. Plat Beton Lantai II 1:2:3 & 0 days & 0 days & KRITIS \\
\hline Pek. Kolom Utama Beton 40/40 1:2:3 & 0 days & 0 days & KRITIS \\
\hline Pek. Besi Stek Kolom Praktis Lt.1 $(10 \mathrm{~kg})$ & 0 days & 0 days & KRITIS \\
\hline Pek. Besi Stek Kolom Praktis Lt.2 $(10 \mathrm{~kg})$ & 0 days & 0 days & KRITIS \\
\hline
\end{tabular}




\section{PERT (Project Evaluation and Review \\ Technique)}

Pada PERT digunakan konsep angka estimasi untuk suatu kegiatan, waktu "Probability" dengan memberikan perkiraan optimasi, waktu pesimistis, dan waktu paling rentang waktu yang lebih besar yaitu tiga

mungkin. Dapat dilihat pada Tabel 4.3. di bawah ini :

Tabel 4.3. Daftar Aktivitas Utama, Waktu Optimis, Paling Mungkin, dan Waktu Pesimis, Standar Deviasi dan Varians Kegiatan

\begin{tabular}{|c|c|c|c|c|c|c|c|c|}
\hline \multirow{2}{*}{ No } & \multirow{2}{*}{\multicolumn{2}{|c|}{ Aktivitas Utama }} & \multicolumn{3}{|c|}{ Waktu } & \multirow{2}{*}{ te } & \multirow{2}{*}{$\mathrm{S}$} & \multirow{2}{*}{$\mathrm{V}(\mathrm{te})$} \\
\hline & & & A & $\mathrm{m}$ & $\mathrm{b}$ & & & \\
\hline \multicolumn{9}{|c|}{ I.PEKERJAAN BANGUNAN KELILING } \\
\hline 1 & $\mathbf{I}$ & PEKERJAAN PERSIAPAN & 12 & 14 & 17 & 14,17 & 0,83 & 0,69 \\
\hline 2 & II & PEKERJAAN TANAH & & & & & & \\
\hline 3 & $\mathrm{~A}$ & Galian Tanah Pondasi Telapak & 14 & 17 & 20 & 17,00 & 1,00 & 1,00 \\
\hline 4 & $\mathrm{~B}$ & Galian Tanah Pondasi Batu Kali/Gunung & 12 & 15 & 19 & 15,17 & 1,17 & 1,36 \\
\hline 5 & III & PEKERJAAN URUGAN & & & & & & \\
\hline 6 & A & Urugan Kembali Galian Poer (Tanah) & 15 & 15 & 20 & 15,83 & 0,83 & 0,69 \\
\hline 7 & $\mathrm{~B}$ & Urugan Kembali Galian Pondasi Garis (Tanah) & 15 & 16 & 21 & 16,67 & 1,00 & 1,00 \\
\hline 8 & $\mathrm{C}$ & Urugan Tanah Dipadatkan & 15 & 16 & 20 & 16,50 & 0,83 & 0,69 \\
\hline 9 & IV & PEKERJAAN PONDASI & & & & & & \\
\hline 10 & $\mathrm{~A}$ & Pasangan Batu Kosong & 12 & 16 & 20 & 16,00 & 1,33 & 1,78 \\
\hline 11 & $\mathrm{~B}$ & Pasangan Pondasi Batu Kali/Gunung 1:5 & 16 & 21 & 30 & 21,67 & 2,33 & 5,44 \\
\hline 12 & $\mathbf{V}$ & PEKERJAAN BETON & & & & & & \\
\hline 13 & A & Pek. Lantai Kerja Pondasi Tapak & 14 & 17 & 20 & 17,00 & 1,00 & 1,00 \\
\hline 14 & $\mathrm{~B}$ & Pek. Beton Tapak 150x150 & 17 & 20 & 25 & 20,33 & 1,33 & 1,78 \\
\hline 15 & $\mathrm{C}$ & Pek. Beton Tapak $75 \times 150$ & 18 & 21 & 24 & 21,00 & 1,00 & 1,00 \\
\hline 16 & $\mathrm{D}$ & Pek. Sloof Beton Bertulang 25/40 1:2:3 & 18 & 21 & 25 & 21,17 & 1,17 & 1,36 \\
\hline 17 & $\mathrm{E}$ & Pek. Sloof Beton Bertulang 20/25 1:2:3 & 18 & 21 & 25 & 21,17 & 1,17 & 1,36 \\
\hline 18 & $\mathrm{~F}$ & Pek. Kolom Utama Beton 40/40 1:2:3 & 15 & 18 & 21 & 18,00 & 1,00 & 1,00 \\
\hline 19 & $\mathrm{G}$ & Pek. Kolom Utama Beton 20/40 1:2:3 & 19 & 21 & 24 & 21,17 & 0,83 & 0,69 \\
\hline 20 & $\mathrm{H}$ & Pek. Pilar 20/75 1:2:3 & 15 & 19 & 22 & 18,83 & 1,17 & 1,36 \\
\hline 21 & I & Pek. Balok Utama 30/60 1:2:3 & 17 & 21 & 24 & 20,83 & 1,17 & 1,36 \\
\hline 22 & $\mathrm{~J}$ & Pek. Balok Anak 15/35 1:2:3 & 16 & 20 & 24 & 20,00 & 1,33 & 1,78 \\
\hline 23 & $\mathrm{~K}$ & Pek. Balok Sunscreen 15/35 1:2:3 & 10 & 20 & 25 & 19,17 & 2,50 & 6,25 \\
\hline 24 & $\mathrm{~L}$ & Pek. Plat Sunscreen Beton 1:2:3 & 19 & 21 & 27 & 21,67 & 1,33 & 1,78 \\
\hline 25 & $\mathrm{M}$ & Pek. Balok Listplank Beton 1:2:3 & 18 & 20 & 26 & 20,67 & 1,33 & 1,78 \\
\hline 26 & $\mathrm{~N}$ & Pek. Plat Beton Lantai II 1:2:3 & 15 & 19 & 22 & 18,83 & 1,17 & 1,36 \\
\hline 27 & $\mathrm{O}$ & Pek. Cor Lantai Kerja 1:2:3 & 15 & 21 & 26 & 20,83 & 1,83 & 3,36 \\
\hline 28 & $\mathrm{P}$ & Pek. Tangga Beton & 16 & 19 & 23 & 19,17 & 1,17 & 1,36 \\
\hline 29 & VI & F. PEKERJAAN SALURAN & & & & & & \\
\hline
\end{tabular}




\begin{tabular}{|c|c|c|c|c|c|c|c|c|}
\hline 30 & A & Pek. Galian Tanah Saluran & 7 & 8 & 12 & 8,50 & 0,83 & 0,69 \\
\hline 31 & $\mathrm{~B}$ & Pek. Pondasi Batu Kali 1:3 & 7 & 9 & 14 & 9,50 & 1,17 & 1,36 \\
\hline 32 & $\mathrm{C}$ & Pek. Cor Plat Saluran 1:2:3 & 7 & 9 & 14 & 9,50 & 1,17 & 1,36 \\
\hline 33 & $\mathrm{D}$ & Pek. Plesteran Dinding Saluran 1:3 & 7 & 8 & 13 & 8,67 & 1,00 & 1,00 \\
\hline 34 & VII & PEKERJAAN BESI STEK & & & & & & \\
\hline 35 & A & Pek. Besi stek Kolom Praktis Lt.1 (10 kg) & 12 & 15 & 18 & 15,00 & 1,00 & 1,00 \\
\hline 36 & $\mathrm{~B}$ & Pek. Besi stek Kolom Induk Lt.2 (10 kg) & 12 & 16 & 18 & 15,67 & 1,00 & 1,00 \\
\hline \multicolumn{9}{|c|}{ II. PEKERJAAN BANGUNAN TENGAH } \\
\hline 37 & VIII & PEKERJAAN GALIAN TANAH & & & & & & \\
\hline 38 & A & Galian Tanah Pondasi Tapak & 13 & 17 & 20 & 16,83 & 1,17 & 1,36 \\
\hline 39 & $\mathrm{~B}$ & Galian Tanah Pondasi Batu Kali/Gunung & 13 & 17 & 22 & 17,17 & 1,50 & 2,25 \\
\hline 40 & IX & PEKERJAAN URUGAN & & & & & & \\
\hline 41 & A & Urugan Kembali Galian Poer (Tanah) & 7 & 9 & 12 & 9,17 & 0,83 & 0,69 \\
\hline 42 & $\mathrm{~B}$ & Urugan Kembali Galian Pondasi Garis (Tanah) & 7 & 7 & 13 & 8,00 & 1,00 & 1,00 \\
\hline 43 & $\mathrm{C}$ & Urugan Tanah Dipadatkan & 6 & 6 & 13 & 7,17 & 1,17 & 1,36 \\
\hline 44 & $\mathbf{X}$ & PEKERJAAN PONDASI & & & & & & \\
\hline 45 & A & Pasangan Batu Kosong & 12 & 17 & 20 & 16,67 & 1,33 & 1,78 \\
\hline 46 & $\mathrm{~B}$ & Pasangan Pondasi Batu Kali/Gunung 1:5 & 14 & 17 & 21 & 17,17 & 1,17 & 1,36 \\
\hline 47 & $\mathbf{X I}$ & PEKERJAAN BETON & & & & & & \\
\hline 48 & A & Pek. Lantai Kerja Pondasi Tapak & 15 & 19 & 22 & 18,83 & 1,17 & 1,36 \\
\hline 49 & $\mathrm{~B}$ & Pek. Beton Tapak 150x150 & 19 & 21 & 26 & 21,50 & 1,17 & 1,36 \\
\hline 50 & $\mathrm{C}$ & Pek. Beton Tapak 75x150 & 19 & 23 & 29 & 23,33 & 1,67 & 2,78 \\
\hline 51 & $\mathrm{D}$ & Pek. Sloof Beton Bertulang 25/40 1:2:3 & 19 & 22 & 27 & 22,33 & 1,33 & 1,78 \\
\hline 52 & $\mathrm{E}$ & Pek. Sloof Beton Bertulang 20/25 1:2:3 & 19 & 21 & 24 & 21,17 & 0,83 & 0,69 \\
\hline 53 & $\mathrm{~F}$ & Pek. Kolom Utama Beton 40/40 1:2:3 & 15 & 22 & 25 & 21,33 & 1,67 & 2,78 \\
\hline 54 & G & Pek. Balok Utama 30/60 1:2:3 & 18 & 21 & 23 & 20,83 & 0,83 & 0,69 \\
\hline 55 & $\mathrm{H}$ & Pek. Balok Anak 15/35 1:2:3 & 20 & 23 & 27 & 23,17 & 1,17 & 1,36 \\
\hline 56 & I & Pek. Balok Sunscreen Beton 1:2:3 & 16 & 19 & 22 & 19,00 & 1,00 & 1,00 \\
\hline 57 & $\mathrm{~J}$ & Pek. Plat Sunscreen Beton 1:2:3 & 15 & 17 & 20 & 17,17 & 0,83 & 0,69 \\
\hline 58 & $\mathrm{~K}$ & Pek. Plat Beton Lantai II 1:2:3 & 14 & 21 & 28 & 21,00 & 2,33 & 5,44 \\
\hline 59 & $\mathrm{~L}$ & Pek. Cor Lantai Kerja 1:2:3 & 15 & 18 & 20 & 17,83 & 0,83 & 0,69 \\
\hline 60 & $\mathrm{M}$ & Pek. Tangga Beton & 15 & 17 & 20 & 17,17 & 0,83 & 0,69 \\
\hline 61 & XII & PEKERJAAN BESI STEK & & & & & & \\
\hline 62 & A & Pek. Besi stek Kolom Praktis Lt.1 (10 kg) & 15 & 15 & 19 & 15,67 & 0,67 & 0,44 \\
\hline 63 & $\mathrm{~B}$ & Pek. Besi stek Kolom Induk Lt.2 (10 kg) & 11 & 15 & 19 & 15,00 & 1,33 & 1,78 \\
\hline
\end{tabular}

Sumber: Data Primer yang Diolah, 2015

Keterangan:

$\mathrm{a}, \mathrm{m}$ dan $\mathrm{b}=$ hasil konsultasi dengan estimator (kontraktor PT. Baharu Sejati).

Dari hasil estimasi dari kontraktor PT.Baharu Sejati diatas didapat hasil dari varians dan deviasi standar dapat dilihat di Tabel 4.4. dibawah ini: 
Tabel 4.4. Varians dan Deviasi Standar Proyek

\begin{tabular}{|c|l|c|}
\hline \multirow{2}{*}{ No } & \multicolumn{1}{|c|}{ Aktivitas/Kegiatan } & V(te) \\
\hline 1 & Pekerjaan Persiapan & 0,69 \\
\hline 2 & Pek. Pilar 20/75 1:2:3 & 1,36 \\
\hline 3 & Pek. Balok Utama 30/60 1:2:3 & 1,36 \\
\hline 4 & Pek. Balok Anak 15/35 1:2:3 & 1,78 \\
\hline 5 & Pek. Balok Sunscreen 15/35 1:2:3 & 6,25 \\
\hline 6 & Pek. Plat Sunscreen Beton 1:2:3 & 1,78 \\
\hline 7 & Pek. Balok Listplank Beton 1:2:3 & 1,78 \\
\hline 8 & Pek. Plat Beton Lantai II 1:2:3 & 1,36 \\
\hline 9 & Pek. Kolom Utama Beton 40/40 1:2:3 & 2,78 \\
\hline 10 & Pek. Besi Stek Kolom Praktis Lt.1 $(10 \mathrm{~kg})$ & 0,44 \\
\hline 11 & Pek. Besi Stek Kolom Praktis Lt.2 $(10 \mathrm{~kg})$ & 1,78 \\
\hline \multicolumn{2}{|c|}{ Varians Proyek $\mathbf{\Sigma}$ V(te) } & 13,22 \\
\hline \multicolumn{2}{|c|}{ Deviasi Standar Proyek } & $\mathbf{3 , 6 4}$ \\
\hline
\end{tabular}

Sumber: Data Primer yang Diolah, 2015

$\mathrm{Z}=$ (batas waktu-waktu penyelesaian yang diharapkan)/deviasi standar proyek

$\mathrm{Z}=(170-162,17) / 3,64$

$$
=2,15
$$

Dengan menggunakan Kurva Distribusi Normal, untuk angka $\mathrm{Z}=2,15$ didapatkan angka "probabilitas" sebesar 0,9842 atau 98,42\%. Hal ini menunjukkan bahwa kemungkinan (probability) proyek selesai pada target waktu 162,17 hari adalah sebesar 98,42\%.

\section{Percepatan Durasi Proyek atau Project Crashing}

Setelah dilakukan analisis dengan berbagai cara, antara lain: menambah sumber daya berkualitas, penambahan waktu kerja (lembur), mengatur kembali jadwal yang terlambat maupun saling tukar tenaga kerja yang memiliki keahlian yang sama. Namun, pada penelitian ini dilakukan dengan mengatur kembali penjadwalan dan penambahan waktu kerja lembur agar lebih cepat dari rencana awal 170 hari kalender menjadi 162,17 hari kalender untuk mencapai target penyelesaian proyek lebih awal dari rencana awal pekerjaan proyek. Dapat dilihat Gambar 4.2 dan Gambar 4.3. di bawah ini sebelum melakukan kerja lembur dan sesudah melakukan kerja lembur. 


\begin{tabular}{|c|c|c|c|c|}
\hline & \multicolumn{2}{|l|}{ Start } & \multicolumn{2}{|c|}{ Finish } \\
\hline Current & \multicolumn{2}{|r|}{ Mon 02/01/12 } & & Tue $24 / 04 / 12$ \\
\hline Baseline & \multicolumn{2}{|r|}{ NA } & \multicolumn{2}{|r|}{ NA } \\
\hline Actual & \multicolumn{2}{|r|}{ NA } & \multicolumn{2}{|r|}{ NA } \\
\hline Variance & \multicolumn{2}{|r|}{ od } & \multicolumn{2}{|r|}{ od } \\
\hline & Duration & \multicolumn{2}{|c|}{ Work } & Cost \\
\hline Current & $170 d$ & \multicolumn{2}{|r|}{$42.478,52 \mathrm{~h}$} & Rp8.775.686.914 \\
\hline Baseline & od? & \multicolumn{2}{|r|}{$\mathrm{Oh}$} & Rp0 \\
\hline Actual & od & \multicolumn{2}{|r|}{ Oh } & Rp0 \\
\hline Remaining & $170 \mathrm{~d}$ & \multicolumn{2}{|r|}{$42.478,52 \mathrm{~h}$} & Rp8.775.686.914 \\
\hline
\end{tabular}

Gambar 4.2. Sebelum melakukan kerja lembur

\begin{tabular}{|c|c|c|c|c|}
\hline & \multicolumn{2}{|l|}{ Start } & \multicolumn{2}{|c|}{ Finish } \\
\hline Current & \multicolumn{2}{|r|}{ Thu $22 / 12 / 11$} & \multicolumn{2}{|r|}{ Sun $13 / 05 / 12$} \\
\hline Baseline & \multicolumn{2}{|r|}{ NA } & \multicolumn{2}{|r|}{ NA } \\
\hline Actual & \multicolumn{2}{|r|}{ NA } & \multicolumn{2}{|r|}{ NA } \\
\hline Variance & \multicolumn{2}{|r|}{ od } & \multicolumn{2}{|r|}{$\mathrm{Od}$} \\
\hline & Duration & \multicolumn{2}{|c|}{ Work } & Cost \\
\hline Current & $162,17 \mathrm{~d}$ & \multicolumn{2}{|r|}{$243.619,83 \mathrm{~h}$} & Rp8.857.795.386 \\
\hline Baseline & od? & & $\mathrm{Oh}$ & Rpo \\
\hline Actual & od & \multirow{2}{*}{\multicolumn{2}{|c|}{$\frac{0 h}{243.619,83 h}$}} & RpO \\
\hline Remaining & $162,17 \mathrm{~d}$ & & & Rp8.857.795.386 \\
\hline
\end{tabular}

Gambar 4.3. Sesudah melakukan kerja lembur

Sehingga, dari analisis kedua tabel di atas untuk perhitungan biaya proyek akibat percepatan durasi proyek dapat dilihat dari Tabel 4.5 di bawah ini :

Tabel 4.5 Perbandingan Keadaan Sebelum dan Sesudah Crashing dengan Alternatif penambahan kerja lembur

\begin{tabular}{|c|c|c|}
\hline Keterangan & $\begin{array}{c}\text { Keadaan sebelum } \\
\text { Crashing }\end{array}$ & $\begin{array}{c}\text { Keadaan sesudah } \\
\text { Crashing }\end{array}$ \\
\hline Hari & 170 & 162,17 \\
\hline Jam Kerja & 42478,52 & 243619,83 \\
\hline Biaya & Rp. 8.775.686.914,00 & Rp. 8.857.795.386,00 \\
\hline
\end{tabular}

Sumber: Data Primer yang Diolah, 2015

\section{Interprestasi Hasil}

Metode PERT dalam penelitian ini ditujukan untuk mencari peluang dan probabilitas penyelesaian proyek. Batas waktu penyelesaian proyek adalah 170 hari, kemudian dilakukan percepatan durasi 162.17 hari, dengan menentukan nilai $\mathrm{Z}$ dapat diketahui peluang pencapaian target penyelesaian proyek. Nilai $\mathrm{Z}$ atau peluang yang didapat sebesar 2,15 berarti ada peluang 98,42\% (berdasarkan kurva distribusi normal).

Untuk analisis percepatan kegiatan dengan metode CPM didapatkan hasil yaitu 
bahwa pada proses percepatan terjadi percepatan maksimum pada saat proyek dapat dipercepat hingga 162,17 hari dari waktu rencana semula 170 hari.

Berdasarkan tabel di atas dapat dilihat terjadinya peningkatan biaya akibat pemendekan durasi pelaksanaan pekerjaan dari 170 hari kerja menjadi 162,17 hari kerja. Sehingga, biaya proyek naik menjadi Rp.8.857.795.386,00 dari rencana biaya sebelum dilakukan percepatan yaitu Rp 8.775.686.914,00. Dengan demikian terjadi pengurangan waktu proyek selama 7,83 hari dan kenaikan biaya sebesar Rp 82.108.472,00 pada saat percepatan mencapai maksimum.

\section{KESIMPULAN DAN SARAN Kesimpulan}

1. Dengan menggunakan analisis jaringan kerja metode PERT dan CPM dapat dilakukan upaya percepatan durasi proyek dengan mempercepat pekerjaan-pekerjaan yang berada pada lintasan kritis.

2. Peluang pencapaian target waktu penyelesaian proyek yang diharapkan yaitu 162,17 hari adalah $98,42 \%$ (nilai Z atau peluang 2,15 ).

3. Percepatan durasi proyek dilakukan dengan mengatur kembali penjadwalan dan penambahan waktu kerja lembur agar lebih cepat dari rencana awal 170 hari kalender menjadi 162,17 hari kalender dengan total pencapaian biaya Rp.8.857.795.386,00 dari biaya awalnya Rp.8.775.686.914,00.

4. Biaya proyek naik menjadi Rp.8.857.795.386,00 dari rencana biaya sebelum dilakukan percepatan yaitu Rp.8.775.686.914,00. Dengan demikian terjadi pengurangan waktu proyek selama 7,83 hari dan kenaikan biaya sebesar Rp.82.108.472,00 pada saat percepatan mencapai maksimum.

\section{Saran}

1. Untuk penelitian selanjutnya sebaiknya diperluas lagi dengan menggunakan metode percepatan durasi proyek yang lain yang tidak digunakan dalam penelitian ini, sehingga dapat dijadikan bahan pembanding untuk mendapatkan kombinasi metode percepatan yang optimal.

2. Dalam merencanakan waktu proyek, perlunya diketahui indikasi berapa persen kemungkinan tercapainya target jadwal untuk suatu kegiatan/waktu proyek agar dapat dipersiapkan langkah-langkah yang diperlukan secara lebih optimal.

3. Perlunya pengendalian waktu dan biaya sejak dini dalam mengantisipasi waktu penyelesaian proyek agar tidak mengalami keterlambatan.

4. Perlunya pembahasan ulang yang berkenaan dengan metode PERT maupun CPM, khususnya untuk proyek yang lebih besar.

\section{DAFTAR PUSTAKA}

Ervianto, Wulfram I., (2005), Manajemen Proyek Konstruksi. Yogyakarta: Andi. Badri, S. 1997. Dasar-dasar Network Planing. Jakarta : PT Rika Cipta.

Ervianto, Wulfram I., "Teori Aplikasi Manajemen Proyek Kontruksi”, Andi Yogyakarta 2004.

Ervianto, Wulfram I., Manajemen Proyek Konstruksi, CV Andi Offset, Yogyakarta, 2002

Handoko, T.H. 1999. Dasar-dasar Manajemen Produksi Dan Operasi, Edisi Pertama. BPFE : Yogyakarta.

Retno Maharesi, 2002. Penjadwalan Proyek dengan Menggabungkan Metode PERT dan CPM.

Tampubolon, Manahan P. 2004. Manajemen Operasional. Jakarta: PT. Ghalia Indonesia.

Dannyanti, Eka. 2010. Studi Kasus Twin Tower Building Pasca Sarjan Undip, Optimalisasi Pelaksanaan Proyek Dengan Metode PERT dan CPM .

Hayun, Anggara. 2005. "Perencanaan dan Pengendalian Proyek dengan Metode PERT-CPM :StudiKasus Fly Over Ahmad Yani, Karawang." Journal The Winners, Vol. 6, No.2, h. 155-174.

Heizer, Jay dan Barry Render. 2005. Operations Management :Manajemen Operasi. Jakarta: Salemba Empat. 
Levin, Richard I. dan Charles A Kirkpatrick. 1972. Perentjanaan dan Pengawasan Dengan PERT dan CPM. Jakarta : Bhratara.

Maharany, Leny dan Fajarwati. 2006. "Analisis Optimasi Percepatan Durasi Proyek dengan Metode Least Cost Analysis." Utilitas, Vol. 14, No. 1, h. 113-130.

Sandyavitri, Ari. 2008. "Pengendalian Dampak Perubahan Desain Terhadap Waktu dan Biaya Pekerjaan Konstruksi”. Jurnal Tehnik Sipil, h.57-70.

Soeharto, Iman. 1995. Manajemen Proyek : Dari Konseptual Sampai Operasional. Jakarta:Erlangga.

Indriarso, H.R. 2003. 'Pemakaian Metode PERT Dan CPM Sebagai Alat Untuk Mengevaluasi Waktu Dan Biaya Proyek".

Soehendradjati RJB, 1987, Manajemen Konstruksi, Jurusan Teknik Sipil Universitas Gadjah Mada, Yogyakarta.

Michael I. Callahan, Daniel G. Quackenbush, AIA, James E. Rowings P.E., 1992, Construction Project Schedulling, John Willey \& Sons, New York.

Husen, Abrar, 2009,Manajemen Proyek, Perencanaan, Penjadwalan, \&
Pengendaliaan Proyek, Penerbit Andi Yogyakarta.

Budi Santosa, 2002, Jurnal Ilmiah FTSP Universitas Gundarma, Keberadaan Profesi Manajemen Konstruksi Di Indonesia,

Jean Couillard, 1995, The Role of Project Risk in Determining Project Management Approac.

Burke Rory, "Project Manajement Planning dan Control Techniques" Promatec International 15 walker Road Statford Upon Avon, England 1999.

Tarliah Dimyati T, Dimyati A, "Operation Research : Model-Model Pengambilan Keputusan", Sinar baru Algesindo 1998

Yudakusumah, T.,W.I., Optimasi Waktu dan Biaya pada Jaringan Kerja Critical Path Method (CPM) dan Precedence Diagram Method (PDM). UNDIP.Semarang.2008

Koesmargono, 1998, Optimasi jadwal Konstruksi, Fakultas Teknik, Universitas Atma Jaya Yogyakarta.

Kaming, P.F., Ervianto, W.I., Fabro, H., 2000, Analisis Durasi Aktivitas Proyek Konstruksi, Vastha No.01/Th. VII, Jan 2000. 